\title{
SPLENIC VEIN PRESSURE IN CONGESTIVE SPLENOMEGALY (BANTI'S SYNDROME)
}

\author{
By WILLIAM P. THOMPSON, JOHN L. CAUGHEY, ALLEN O. WHIPPLE \\ AND LOUIS M. ROUSSELOT
}

(From the Spleen Clinic of the Presbyterian Hospital, New York City)

(Received for publication March 8, 1937)

The possibility that Banti's syndrome may be the result of some common factor operating within the portal system is suggested by the variety of disturbances that appear to be associated with this clinical picture $(1,2,3,4,5,6)$.

From a study of a relatively large number of patients presenting this syndrome of anemia, leukopenia and thrombocytopenia with splenomegaly, we were impressed by the possibility that a common factor might be increased portal vein pressure. We observed the Banti syndrome in association with cirrhosis of the liver, with partial and progressive obstruction of the splenic vein by neoplasms and thrombi, and in the later stages of schistosomiasis infestation. Portal hypertension might conceivably be present in all and portal hypertension might be a factor common to all.

If portal hypertension is a factor it should be possible to determine its presence and to measure its degree by direct readings at operation. Observations on the splenic vein pressure have now been made in 15 cases by inserting the needle of the venous pressure apparatus into the splenic vein after delivery of the spleen and before ligation of any of the larger splenic vessels.

It is important to have the level of the venous pressure manometer adjusted to the cardiac level before the operation is started. It is also important to be sure that the readings are taken without excessive traction on or distortion of the splenic vessels.

In several of the 15 cases studied technical surgical difficulties interfered, and the results are open to question. In two instances the exact clinical diagnosis remained doubtful even after operation and microscopic study of the liver and spleen.

There have been, however, 8 cases of Banti's syndrome in which the associated lesion could be definitely established and in which accurate venous pressure readings were obtained. In addition there have been 3 cases of hemolytic jaundice to serve at least as a beginning of a control series.

Of the 8 cases with Banti's syndrome in 3 , the splenomegaly was associated with chronic infestation by schistosoma Mansoni. In the schistosomiasis cases Banti's syndrome appeared gradually with slowly progressive splenic enlargement and slowly progressive anemia, leukopenia and thrombocytopenia. In all, sections of the removed spleen showed the diffuse fibrosis and the perifollicular congestion that is typical of the Banti type of splenomegaly, and liver biopsy revealed the typical schistosomal type of liver cirrhosis with remnants of ova in the periportal spaces. In all, splenectomy was followed by a prompt return of the blood values to normal.

TABLE I

Splenic vein pressure in 3 cases of Banti's syndrome associated with chronic schistosomiasis

\begin{tabular}{|c|c|c|}
\hline Case & $\begin{array}{l}\text { Splenic vein } \\
\text { pressure }\end{array}$ & $\begin{array}{l}\text { Simultaneous arm } \\
\text { vein pressure }\end{array}$ \\
\hline $\begin{array}{l}\text { 1. P. P } \\
\text { 2. A. } \\
\text { 3. G. F }\end{array}$ & 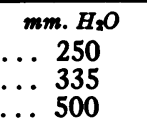 & $\begin{array}{c}\text { mm. } H_{2} \mathrm{O} \\
50 \\
105 \\
70\end{array}$ \\
\hline
\end{tabular}

Splenic vein pressure readings were obtained in 5 cases of Banti's syndrome associated with the Laennec type of liver cirrhosis.

TABLE II

Splenic vein pressure in 5 cases of Banti's syndrome associated with Laennec's cirrhosis

\begin{tabular}{|c|c|c|}
\hline Case & $\begin{array}{l}\text { Splenic vein } \\
\text { pressure }\end{array}$ & $\begin{array}{l}\text { Simultaneous arm } \\
\text { venous pressure }\end{array}$ \\
\hline $\begin{array}{l}\text { 4. C. I } \\
\text { 5. G. I } \\
\text { 6. D. I } \\
\text { 7. L. I } \\
\text { 8. N. }\end{array}$ & $\begin{array}{ll} & m . H_{2} \mathrm{O} \\
\therefore .275 \\
\because .325 \\
\because .450 \\
\because .275 \\
. \quad 470\end{array}$ & $\begin{array}{c}m m . H_{3} O \\
12 \\
85 \\
125 \\
105 \\
140\end{array}$ \\
\hline
\end{tabular}

Three cases of typical hemolytic jaundice serve as the only controls we have as yet been able to study. 
TABLE III

Splenic vein pressure in 3 cases of typical hemolytic jaundice

\begin{tabular}{|c|c|c|}
\hline Case & $\begin{array}{c}\text { Splenic vein } \\
\text { pressure }\end{array}$ & $\begin{array}{l}\text { Simultaneous arm } \\
\text { venous pressure }\end{array}$ \\
\hline $\begin{array}{l}\text { 9. R. B } \\
\text { 10. N. E } \\
\text { 11. W. }\end{array}$ & 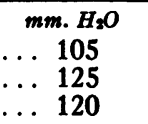 & $\begin{array}{c}\text { mm. } \mathrm{H}_{2} \mathrm{O} \\
80 \\
130 \\
85\end{array}$ \\
\hline
\end{tabular}

DISCUSSION

The relatively great increase in splenic vein pressure in cases presenting Banti's syndrome when compared with the venous pressure simultaneously recorded in the arm suggests that portal hypertension may be an important factor in the production of the chronic splenomegaly.

The use of cases of hemolytic jaundice as controls is, of course, not entirely satisfactory, but the fact that in 3 instances the splenic and arm vein pressure were approximately the same suggests that portal hypertension is not a factor in this disease.
The importance of obtaining pressure readings in patients with cirrhosis but without splenomegaly is appreciated, and data on patients with chronic passive congestion due to cardiac failure would be of interest. The difficulties involved in obtaining such measurements are obvious.

\section{BIBLIOGRAPHY}

1. McMichael, J., The pathology of hepatolienal fibrosis. J. Path. and Bact., 1934, 39, 481.

2. McMichael, J., Local vascular changes in splenic anemia. Edinburgh M. J., 1931, 38, 1.

3. McNee, J. W., The spleen: its structure, functions and diseases. Lancet, 1931, 1, 951.

4. Rousselot, Louis M., The rôle of congestion (portal hypertension) in so-called Banti's syndrome. A clinical and pathologic study of 31 cases with the late results following splenectomy. J. A. M. A., 1936, 107, 1788.

5. Johnston, J. M., The relation of changes in the portal circulation to splenomegaly of the Banti's type. Ann. Int. Med., 1930-31, 4, 772.

6. Larrabee, R. C., Chronic congestive splenomegaly and its relationship to Banti's disease. Am. J. M. Sc., 1934, 188, 745. 